\title{
Screening of postpartum depression among new mothers in Istanbul: a psychometric evaluation of the Turkish Edinburgh Postnatal Depression Scale
}

\author{
Perran Boran ${ }^{1 \dagger}$, Ahmed Waqas ${ }^{2 *}{ }^{*}$ (1), Öykü Özbörü Aşkan ${ }^{1}$, Irem Topçu' ${ }^{1}$, Tugay Dogan ${ }^{1}$ and Atif Rahman ${ }^{3}$
}

\begin{abstract}
Objective: This study is the first concerted effort to ascertain factor structure of EPDS using evidence based analytical techniques. It is the most widely used scale for assessing postpartum depression in Turkey, and yet no investigations have been conducted to assess it factor structure. This study was conducted from April 2012 to April 2018 at the Marmara University Hospital operating under the name of Marmara University Pendik Training and Research Hospital in Istanbul Turkey.

Results: A total of 1700 women were included in this study, who responded to the EPDS, in addition to demographic characteristics and well-being of their offspring. A total of 1615 mothers provided adequate data for inclusion in analysis. Standardized Chronbach's alpha for EPDS was 0.81 with corrected item-total correlations ranging from 0.35 to 0.62. Parallel analysis, MAP Velicer Test and Hull's method dictated retaining of one factor structure. All the items revealed adequate communalities (>0.20) except item 2 (enjoyment) and item 10 (self-harm). Their communalities were 0.16 and 0.19 , however, these items were not dropped. All of the items yielded moderate to strong factor loadings. Minimum factor loading was for item 2 (0.40) and highest for item 8 (0.71).
\end{abstract}

Keywords: Edinburgh Postnatal Depression Scale, Turkey, Validation, Reliability

\section{Introduction}

Postpartum depression (PPD) is a debilitating common mental disorder and constitutes a major global health concern [1]. Recent estimates place the prevalence of postpartum depression at $19.8 \%(19.5-20.0)$ post-birth [1]. These high prevalence estimates have also been reported among Turkish mothers, ranging from 21 to $36 \%$ [2-4]. Two meta-analysis including over 50 studies, estimate the weighted mean prevalence of PPD to be around $24 \%$ in Turkey $[5,6]$. Studies from around the

*Correspondence: ahmedwaqas1990@hotmail.com

†Perran Boran and Ahmed Waqas equal first authors

${ }^{2}$ Human Development Research Foundation, F-7/4, Islamabad, Pakistan

Full list of author information is available at the end of the article world have shown association of PPD with poor child outcomes. For instance, mothers with moderate to severe depressive symptoms at 9 months postpartum report children with shorter stature [average $0.26 \mathrm{~cm}$ shorter; $95 \%$ CI $5 \mathrm{~cm}, 48 \mathrm{~cm}$ ] than their counterparts; and this effect persists for first 6 years of child's life [7]. Moreover, postpartum depressive symptoms are also associated with poorer overall child cognitive and physical development [8].

One of the most frequently used instrument used for screening of PPD is the Edinburgh Postnatal Depression Scale (EPDS) [9]. It is a 10-item self-administered scale, developed for detection of PPD in community and primary care settings. Developed on the basis of Research Diagnostic Criteria for depressive illness obtained from 
Goldberg's Standardized Psychiatric Interview [10], it has demonstrated adequate criterion, face and factor validity [10]. The scale is easily comprehensible, completed in a short time $(\sim 5 \mathrm{~min})$ and has a simple scoring pattern. More than $90 \%$ of the studies on PPD, in Turkey, utilize the EPDS scale [5, 6]. A Turkish translation of the EPDS (Additional file 1) was found reliable among a Turkish population in the year 2004, albeit reporting poor criterion validity [4]. No investigations so far have been conducted to ascertain dimensionality, or factor structure of EPDS in Turkey. Therefore, this study aims to validate the EPDS using exploratory and confirmatory factor analytical techniques, to provide a robust evidence for its factor validity and reliability in a Turkish population.

\section{Main text \\ Methods \\ Study design \& setting}

This psychometric validation study is part of a prospective birth cohort study of newborn infants followed up at the well-child outpatient clinic, Marmara University Pendik Training and Research Hospital from the year 2012 to 2018, located in Pendik, Turkey. Since 2012, the outpatient clinic provides care for newborns of the mothers who give birth at the university hospital's maternity clinic. They receive a pamphlet with information regarding how to make an appointment at the well child outpatient clinic. Each term newborn $(\geq 37$ weeks of gestational age) is generally scheduled for a first appointment at 1 month of age and is then followed up regular basis, up to 5 years of age. Mothers are screened for postpartum depression at 1 month well child visit using the EPDS [4]. Ethical approval for this study was taken from the Ethical Review Committee at the Marmara University, Turkey. Written informed consent was taken from all participating mothers.

\section{Statistical analysis}

Recent evidence for minimum sample size recommendations, however, suggest that psychometricians should consider number of number of factors, variables to factor ratio $(\mathrm{p} / \mathrm{f})$, strength of communalities as well as level of criterion for a particular scale [11]. Therefore, keeping recent literature on EPDS, a minimum sample size of 50 seems to be appropriate for wide communalities. $\mathrm{p} / \mathrm{f}(10)$, unidmensional factor structure and excellent criterion $(0.98)[9,10,12,13]$.

All analyses were conducted using SPSS (v.25) and FACTOR software [14]. Visualization of histogram, Q-Q plots as well as values of skewness and kurtosis were used to assess normality in EPDS scores of participants. Floor and ceiling effects were considered significant if $\geq 20 \%$ either scored the lowest or maximum score on EPDS [15].
Internal consistency of the EPDS was tested using the Cronbach's alpha value, Mislevy \& Block and McDonald's Omega, which was considered adequate at $\geq 0.7$ [16-18]. Convergent validity was assessed performing item-scale Pearson's product moment correlations corrected for overlaps, considered adequate at $\geq 0.2$ for all items [19]. To assess the factor structure and dimensionality of EPDS in present sample, exploratory factor analyses was conducted using three techniques namely: Principal Axis Factoring (PFA), Principal Component Analysis (PCA) and Maximum Likelihood technique (ML). We chose to run PFA in addition to ML, because PFA is more robust when the data violates assumptions of multivariate normality [20]. Total number of factors to retain was judged using several criteria including Cattell's Scree plot, parallel analysis based on minimum rank factor analysis, MAP Velicer Test and Hull's method [21]. Thereafter, suitability of each item to include in the final scale was assessed using several criteria: (a) communality $(\geq 0.2)$ and (b) factor loadings $\geq 0.32$.

Confirmatory factor analysis was further run to analyze the goodness of fit of the factor structure of EPDS. Several goodness of normed and non-normed fit indices were utilized including comparative fit index (CFI), normed fit index (NFI), Tucker-Lewis index (TLI), incremental fit index (IFI). While absolute fit indices included the goodness-of-fit index (GFI) and adjusted goodnessof fit index (AGFI) as well as root mean square error of approximation (RMSEA), root mean squared residual (RMR), standard root mean squared residual (SRMR) [22]. Cut-off values for goodness of fit indices were $>0.90$, RMSEA at $<0.08$ or not significantly greater than Kelley's criterion, and $<0.10$ for SRMR [22].

\section{Results}

\section{Demographic characteristics}

EPDS data of 1614 mothers with a mean age of 28.87 years (5.46) was included in the exploratory and confirmatory factor analyses (missing data $\mathrm{n}=86$ ). Mean number of years of education received by mothers were reported to be 8.64 (3.83). Most of the mothers were housewives $1314(81.4 \%), 22(1.4 \%)$ were unqualified workers, $100(6.2 \%)$ low to middle quality workers, 136 (8.54\%) were qualified government workers and 42 (2.6\%) were professional workers.

\section{Face and content validity}

The participants generally reported good comprehensibility of the EPDS scale at the time of administration, pointing to a good face validity. Content validity however, was not assessed as it was done in a previous publication that details the forward and backward translation process and criterion validity of the questionnaire [4]. 


\section{Descriptive statistics}

Mean score on Edinburgh Postnatal Depression Scale (EDPS) was 6.64 (4.63). Visualization of histogram and normal Q-Q plot revealed some degree of non-normality where distribution of total scores on EPDS was mildly skewed (0.78) and non-kurtotic (0.42) (Fig. 1). Mean scores on individual items ranged from 0.08 for item 10 exhibiting fewer symptoms of suicidality to 1.39 for item 3 exhibiting self-blaming or guilt among mothers. Furthermore, symptoms of anxiety (Item 4) and panic (Item 5) were most reported by the mothers (Table 1 ).
Overall, a total of 310 (19.2\%) of the mothers screened positive for depressive symptoms. Symptoms of guilt were reported by 1246 (77.20\%), anxiety 1120 (69.39\%), panic 979 (60.66\%), sadness 893 (55.34\%), poor coping $743(46.03 \%)$, lack of sleep $660(40.89 \%)$, crying spells 650 (40.27\%), anhedonia 240 (14.87\%), decreased mood 230 (14.25\%), and suicidal ideation 90 (5.58\%). Floors and ceiling effects were not evident in total scores of EPDS scale with less $20 \%$ of the respondents scoring either the lowest or highest of the possible scores on EPDS. A total of $99(6.1 \%)$ respondents reported the lowest score on

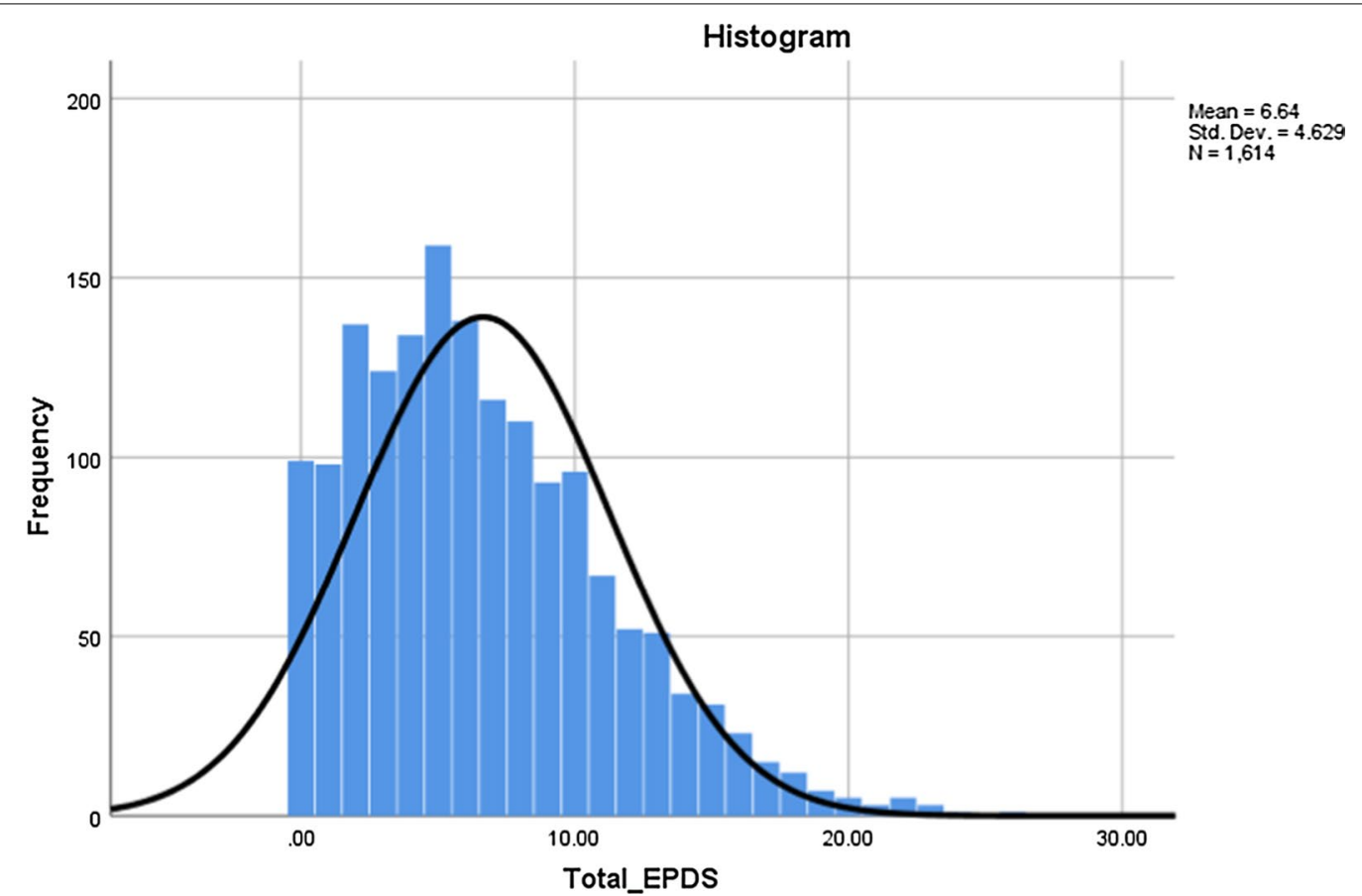

Fig. 1 Histogram presenting distribution of EPDS scores among new Turkish mothers. The histogram shows that distribution of total scores on EPDS was mildly skewed among Turkish mothers

Table 1 Internal consistency and item-total correlations for individual items on EPDS

\begin{tabular}{|c|c|c|c|c|c|}
\hline Item & Mean & SD & $\begin{array}{l}\text { Scale mean } \\
\text { if item deleted }\end{array}$ & $\begin{array}{l}\text { Corrected item- } \\
\text { total correlation }\end{array}$ & $\begin{array}{l}\text { Cronbach's alpha } \\
\text { if item deleted }\end{array}$ \\
\hline 1. I have been able to laugh and see the funny side of things & 0.16 & 0.433 & 6.48 & 0.409 & 0.785 \\
\hline 2. I have looked forward with enjoyment to things & 0.17 & 0.448 & 6.47 & 0.346 & 0.789 \\
\hline 3. I have blamed myself unnecessarily when things went wrong & 1.39 & 0.954 & 5.25 & 0.455 & 0.779 \\
\hline 4. I have been anxious or worried for no good reason & 1.16 & 0.934 & 5.49 & 0.545 & 0.765 \\
\hline 5. I have felt scared or panicky for no very good reason & 1.02 & 0.980 & 5.63 & 0.483 & 0.775 \\
\hline 6. Things have been getting on top of me & 0.83 & 1.003 & 5.82 & 0.507 & 0.772 \\
\hline 7. I have been so unhappy that I have had difficulty sleeping & 0.62 & 0.857 & 6.02 & 0.474 & 0.775 \\
\hline 8. I have felt sad or miserable & 0.71 & 0.802 & 5.93 & 0.619 & 0.756 \\
\hline 9. I have been so unhappy that I have been crying & 0.50 & 0.707 & 6.15 & 0.578 & 0.763 \\
\hline 10. The thought of harming myself has occurred to me & 0.08 & 0.339 & 6.57 & 0.369 & 0.790 \\
\hline
\end{tabular}


EPDS while only $1(0.1 \%)$ reported the highest scores on it. This indicates that psychometric testing using EPDS was fit to measure depressive symptoms and responsive to change without being impaired by floor and ceiling effects.

\section{Reliability and convergent validity}

Standardized Chronbach's alpha for EPDS was 0.81with corrected item-total correlations ranging from 0.35 to 0.62. All the items had adequate item-total correlations, revealing no multicollinearity or singularity and were retained at this stage for exploratory factor analyses. Moreover, inter-item correlation matrix was run to ascertain convergent validity with all items exhibiting a correlation value of 0.2 with at least one other item (Table 1 ). Moreover, other tests for reliability yielded adequate reliability of EPDS as assessed by McDonald's Omega (0.81) and Mislevy \& Bock [18] reliability estimate of 0.83 .

\section{Factor validity}

Prior to running exploratory factor analyses, sampling adequacy was ascertained using the KMO statistics, yielding a good sampling adequacy (0.88), along with a significant Bartlett test of sphericity $\left(x^{2}=3456.03\right.$, $\mathrm{p}<0.001)$. Thereafter, observation of correlation matrix revealed that all EPDS items had yielded a correlation $>0.2$, at least with one other item. Item 9 (crying spells) yielded highest correlation value of 0.54 with Item 8 (sadness). Thus, there were no issues of multicollinearity in the data. Sampling adequacy for each item was measured using KMO measure of sampling adequacy obtained in anti-image correlation matrix. It ranged from 0.863 (Item 1) to 0.915 (Item 7), therefore, yielding marvellous to meritorious KMO values for individual items. Therefore, all items were taken into exploratory factor analyses.
The criteria for determining the number of factors to retain was multifaceted and dependent on several factors including Eigen values $>1$, Cattell's Scree plot as well as more advanced methods such as parallel analysis, Hull's method and MAP Velicer test. A total of 2 factors yielded an Eigen Value greater than 1.0 in present analysis. The first factor had an Eigen value of 3.68 explaining a variance of $36.77 \%$ while the second factor had an Eigen value of 1.10 leading to a cumulative $47.79 \%$ of variance explained by the two factors. However, Cattell's Scree plot favoured a one-dimensional model, demonstrating a sharp drop in Eigen value, from first to second factor. This uni-dimensionality was further confirmed in more advanced statistical analyses such as Parallel analysis. Parallel Analysis was run based on minimum rank factor analysis with 500 replicates (Timmerman and LorenzoSeva 2011). This simulation revealed that the mean of random percentage of variance (18.1\%) explained by second factor was greater than the percentage of variance obtained through EFA (12.9\%). These were further confirmed by Minimum Average Partial Velicer test as well as the Hull Method.

All the items revealed adequate communalities $(>0.20)$ except item 2 (enjoyment) and item 10 (self-harm). Their communalities were 0.16 and 0.19 , however, these items were not dropped. All the items yielded moderate to strong factor loadings (Table 2). Minimum factor loading was for item $2(0.40)$ and highest for item 8 (0.71).

\section{Confirmatory factor analysis}

Confirmatory Factor Analysis with the Exploratory Maximum Likelihood (ML) was run to confirm the goodness of fit for one-dimension structure of EPDS. It revealed that the one-dimension structure for EPDS yielded adequate values for all the indices representing the goodness of fit. It yielded a RMSEA value of $0.066(<0.08)$ which was not significantly greater than

Table 2 Factor loadings for individual items obtained with PFA and ML

\begin{tabular}{|c|c|c|c|c|}
\hline Statements & PAF & ML & PCA & Communalities \\
\hline 1. I have been able to laugh and see the funny side of things & 0.483 & 0.477 & 0.55 & 0.234 \\
\hline 2. I have looked forward with enjoyment to things & 0.400 & 0.395 & 0.47 & 0.160 \\
\hline 3. I have blamed myself unnecessarily when things went wrong & 0.493 & 0.493 & 0.56 & 0.243 \\
\hline 4. I have been anxious or worried for no good reason & 0.592 & 0.591 & 0.65 & 0.350 \\
\hline 5. I have felt scared or panicky for no very good reason & 0.512 & 0.506 & 0.58 & 0.262 \\
\hline 6. Things have been getting on top of me & 0.567 & 0.562 & 0.63 & 0.322 \\
\hline 7. I have been so unhappy that I have had difficulty sleeping & 0.535 & 0.536 & 0.60 & 0.286 \\
\hline 8. I have felt sad or miserable & 0.714 & 0.721 & 0.74 & 0.510 \\
\hline 9. I have been so unhappy that I have been crying & 0.674 & 0.681 & 0.72 & 0.454 \\
\hline 10. The thought of harming myself has occurred to me & 0.434 & 0.435 & 0.50 & 0.188 \\
\hline
\end{tabular}


the cut-off value of 0.05 . And according to Hair et al. (2010) and $\mathrm{Hu}$ and Bentler [22], revealed a good fitness of the model. All goodness of fit indices $>0.90$ including CFI (0.93), TLI (0.91), GFI (0.99), AGFI (0.98), and GFI without diagonal values (0.97). Root Mean Square of Residuals (RMSR) was 0.047 which was not significantly larger than the expected mean value of RMSR for an acceptable model, as obtained by the Kelley's criterion $(4 / \sqrt{ }$ sample size $)$.

\section{Known group analysis with characteristics of mother}

There was significant association of EPDS scores with improved housing index $(\mathrm{r}=0.1, \mathrm{p}<0.05)$ and high income $(r=0.1, p<0.05)$. There were no significant relationships between type of delivery $\left(\chi^{2}=0.69\right.$, $\mathrm{p}>0.05)$, mother's education levels $(\mathrm{p}>0.05)$ and age $(\mathrm{p}>0.05)$.

\section{Discussion}

The present study found EPDS to be a reliable and valid tool based on exploratory and confirmatory factor analyses in a large study sample with $19.2 \%$ of mothers screening positive for depression. Although EPDS is a globally used scale, previous analyses have mainly reported its criterion-validity and data on other aspects of validity especially the factory validity are lacking. This point has been emphasized in several meta-analyses in Africa, Europe and globally $[9,10,13,23,24]$. Akin to this, previous validation study of EPDS among Turkish population, only reported criterion validity [4]. However, measuring criterion validity as the sole measure of validation is inadequate, and it is very essential to conduct construct, content, convergent, and concurrent validity to ascertain the cross-cultural interchangeability for a particular psychometric instrument [25].

The importance of factor validation for EPDS has been emphasized in cross-cultural studies, reporting varying factor solutions for it. For instance, EPDS has exhibited a three factor structure comprising anhedonia, depression and anxiety among the Spanish population [26]. A varied model comprising of subscales of anhedonia, anxiety and low mood was shown as having best fit among Hungarian population [27]. In a similar vein, a three factor structure of EPDS comprising of anhedonia, anxiety and depressive mood has exhibit best model fit indices among the US and Japanese maternal population $[28,29]$. Increasingly reports of heterogeneous factor structures are being reported in other countries [30,31]. Therefore, it is important to test dimensionality of EPDS in different settings before implementing screening clinics for postpartum depression.

\section{Limitations}

Inclusion of a large sample size from an entire district of Turkey favours adequate power of the study and generalizability of its results.

\section{Supplementary information}

Supplementary information accompanies this paper at https://doi. org/10.1186/s13104-020-05196-x.

Additional file 1: Turkish Translation of Edinburgh Postnatal Depression Scale.

\section{Abbreviations}

PPD: Postpartum depression; EPDS: Edinburgh Postnatal Depression Scale; PFA: Principle axis factoring; ML: Maximum likelihood; PCA: Principle component analysis.

\section{Acknowledgements}

Not applicable.

\section{Authors' contributions}

AW, PB and AR conceived the study and performed statistical analysis. AW, PB and AR drafted the manuscript. OOA, IT \& TD participated in the study design, and data collection and revised it critically. All authors read and approved the final manuscript.

Funding

This study has not received any funding.

Availability of data and materials

All data associated with this manuscript are available on request to the corresponding author.

Ethics approval and consent to participate

Ethical approval for this study was taken from the Ethical Review Committee at the Marmara University, Turkey. Written informed consent was taken from all participating mothers, who were ensured anonymity and that only group findings would be reported.

\section{Consent for publication}

Not applicable.

\section{Competing interests}

The authors report no declarations of interest. Dr. Ahmed Waqas serves BMC Research Notes as an associate editor, however, he was not involved in the peer review process for this manuscript.

\section{Author details}

${ }^{1}$ Division of Social Pediatrics, Department of Pediatrics, School of Medicine, Marmara University, İstanbul, Turkey. ${ }^{2}$ Human Development Research Foundation, F-7/4, Islamabad, Pakistan. ${ }^{3}$ Institute of Population Health, University of Liverpool, The Waterhouse Building, Dover St, Liverpool L3 5DA, UK.

Received: 6 May 2020 Accepted: 2 July 2020

Published online: 28 July 2020

\section{References}

1. Fisher J, Cabral de Mello M, Patel V, Rahman A, Tran T, Holton S, et al. Prevalence and determinants of common perinatal mental disorders in women in low- and lower-middle-income countries: a systematic review. Bull World Health Organ. 2012;90:139G-49G.

2. Inandi T, Elci OC, Ozturk A, Egri M, Polat A, Sahin TK, et al. Risk factors for depression in postnatal first year, in eastern Turkey. Int J Epidemiol. 2002;31:1201-7. https://doi.org/10.1093/ije/31.6.1201. 
3. Yağmur Y, Ulukoca N. Social support and postpartum depression in lowsocioeconomic level postpartum women in Eastern Turkey. Int J Public Health. 2010;55:543-9.

4. Aydin N, Inandi T, Yigit A, Nalan Sahin Hodoglugil N. Validation of the Turkish version of the Edinburgh Postnatal Depression Scale among women within their first postpartum year. Soc Psychiatry Psychiatr Epidemiol. 2004;39:483-6.

5. Karaçam Z, Çoban A, Akbaş B, Karabulut E. Status of postpartum depression in Turkey: a meta-analysis. Health Care Women Int. 2018:39:821-41.

6. Özcan NK, Boyacıoğlu NE, Dinç H. Postpartum depression prevalence and risk factors in Turkey: a systematic review and meta-analysis. Arch Psychiatr Nurs. 2017;31:420-8. https://doi.org/10.1016/j.apnu.2017.04.006.

7. Surkan PJ, Ettinger AK, Hock RS, Ahmed S, Strobino DM, Minkovitz CS. Early maternal depressive symptoms and child growth trajectories : a longitudinal analysis of a nationally representative US birth cohort. BMC Pediatrics. 2014;14:1-8.

8. Brentani A, Fink G. Maternal depression and child development: evidence from São Paulo's Western Region Cohort Study. Revista da Associação Médica Brasileira. 2016;62:524-9.

9. Gibson J, Shakespeare J, Price J, Gray RA. A systematic review of studies validating the Edinburgh Postnatal Depression Scale in antepartum and postpartum women. Acta Psychiatrica Scandinavica. 2009;119:350-64.

10. Cox JL, Sagovsky JMHR. Detection of postnatal depression development of the 10-item edinburgh postnatal depression scale. Br J Psychiatry. 1987;150:782-6.

11. Mundfrom DJ, Shaw DG, Ke TL. Minimum sample size recommendations for conducting factor analyses. Int J Test. 2005;5:159-68. https://doi. org/10.1207/s15327574ijt0502_4.

12. Tsai AC, Scott JA, Hung KJ, Zhu JQ, Matthews LT. Reliability and validity of instruments for assessing perinatal depression in african settings: systematic review and meta-analysis. PloS ONE. 2013;8:1-12.

13. Thombs BD, Benedetti A, Kloda LA, Levis B, Riehm KE, Azar M, et al. Diagnostic accuracy of the Edinburgh Postnatal Depression Scale (EPDS) for detecting major depression in pregnant and postnatal women: protocol for a systematic review and individual patient data meta-analyses. BMJ Open. 2015;5:1-8.

14. Lorenzo-Seva U, Ferrando PJ. FACTOR: a computer program to fit the exploratory factor analysis model. Behav Res Methods. 2006;38:88-91.

15. Waqas A, Farooq F, Raza M, Javed ST, Khan S, Ghumman ME, et al. Validation of the internet addiction test in students at a Pakistani medical and dental school. Psychiatr Q. 2017:89:235-47.

16. Streiner DL. Starting at the beginning: an introduction to coefficient alpha and internal consistency. J Pers Assess. 2003;80:99-103.

17. Dunn TJ, Baguley T, Brunsden V. From alpha to omega: a practical solution to the pervasive problem of internal consistency estimation. Br J Psychol. 2014;105:399-412.
18. Mislevy R, Bock R. BILOG 3: Item analysis and test scoring with binary logistic models. 1990.

19. Streiner DL, Norman GR. Health Measurement Scales: a practical guide to their development and use. 2008.

20. Fabrigar LR, MacCallum RC, Wegener DT, Strahan EJ. Evaluating the use of exploratory factor analysis in psychological research. Psychol Methods. 1999;4:272-99.

21. Gaskin CJ, Happell B. On exploratory factor analysis: a review of recent evidence, an assessment of current practice, and recommendations for future use. Int J Nurs Stud. 2014;51:511-21.

22. Hu L, Bentler PM. Cutoff criteria for fit indexes in covariance structure analysis: conventional criteria versus new alternatives. Struct Equ Model A Multidiscip J. 1999;6:1-55.

23. Boere-boonekamp AIVDZDBMM. Screening for postpartum depression in well-baby care settings: a systematic review. Matern Child Health J. 2017;21:9-20

24. Evans K, Spiby H, Morrell CJ. REVIEW PAPER A psychometric systematic review of self-report instruments to identify anxiety in pregnancy. J Adv Nurs. 2015;71:1986-2001.

25. Arafat SMY. Cross cultural adaptation \& psychometric validation of instruments: step-wise description. Int J Psychiatry. 2016;1:4.

26. Gutierrez-zotes A, Gallardo-pujol D, Labad J, Gelabert E, Navinés R, Universitari $\mathrm{H}$, et al. Factor structure of the Spanish version of the edinburgh postnatal depression scale. 2018;46.

27. Kozinszky Z, Töreki A, Emőke A, Dudas RB, Németh G. Author's accepted manuscript. Psychiatry Res. 2017. https://doi.org/10.1016/j.psych res.2017.01.059.

28. Kubota C, Inada T, Nakamura Y, Shiino T, Ando M. Stable factor structure of the Edinburgh Postnatal Depression Scale during the whole peripartum period: results from a Japanese prospective cohort study. Sci Rep. 2018:8:1-7.

29. Chiu YM, Sheffield PE, Hsu HL, Curtin PC, Wright RJ. HHS Public Access. 2018;20:803-10

30. Flom J, Chiu Y, Tamayo-Ortiz M, Schnaas L, Curtin P, Wright R. Subconstructs of the edinburgh postpartum depression scale in a postpartum sample in Mexico City. Physiol Behav. 2018;238:142-6.

31. Tuohy A, McVey C. Subscales measuring symptoms of non-specific depression, anhedonia, and anxiety in the Edinburgh Postnatal Depression Scale. Br J Clin Psychol. 2008;47:153-69.

\section{Publisher's Note}

Springer Nature remains neutral with regard to jurisdictional claims in published maps and institutional affiliations.
Ready to submit your research? Choose BMC and benefit from:

- fast, convenient online submission

- thorough peer review by experienced researchers in your field

- rapid publication on acceptance

- support for research data, including large and complex data types

- gold Open Access which fosters wider collaboration and increased citations

- maximum visibility for your research: over $100 \mathrm{M}$ website views per year

At BMC, research is always in progress.

Learn more biomedcentral.com/submissions 